\title{
Job satisfaction of female office clerks in government, multinational, and local private business concerns of Bangladesh
}

\author{
*Afrina Rahaman ${ }^{1}$, Nafisa Rashid², Nargis Akhter ${ }^{3}$ \\ ${ }^{13}$ Department of Business Administration, East West University, Dhaka-1212, Bangladesh \\ ${ }^{2}$ School of Business Studies, Southeast University Dhaka, Bangladesh \\ *afrinarahaman07@yahoo.com
}

\begin{abstract}
In this study the researchers attempt to make a comparative study among the female office clerks of government, multinational and local private business organizations in Bangladesh regarding their job satisfaction. The study consisted of 255 sample female office clerks of government; multinational and local private business concerns in Bangladesh and convenient method of sampling was used to collect data for this study. Factor analysis, regression analysis were used for analyzing the data. The employers of government, multinational and local private business organizations can take help from this study to know about the job satisfaction of female office clerks of their organizations. The study also opens the scope to make a comparative study on various issues to female office clerks in Bangladesh.
\end{abstract}

Keywords: Job Satisfaction, Female Office Clerks, government, local private, multinational

\section{Introduction}

Gender roles develop through internalization and identification during childhood Sigmund Freud suggested that biology (based around the penis) determines gender identity through identification with either the mother or father. While some people agree with Freud, others argue that the development of the gendered self is not completely determined by biology based around one's relationship to the penis, but rather the interactions that one has with the primary caregiver(s). From birth, parents interact differently with children depending on their sex, and through this interaction parents can instill different values or traits in their children on the basis of what is normative for their sex. This internalization of gender norms can be seen through the example of which types of toys children are typically given ("feminine" toys often reinforce interaction, nurturing, and closeness, "masculine" toys often reinforce independence and competitiveness) that parents give to their children. Education also plays an integral role in the creation of gender norms.

Throughout most of the history female generally have had fewer legal rights and career opportunities than men. Wifehood and motherhood were regarded as female's most significant professions. In the 20th century, however, female in most nations won the right to vote and increased their educational and job opportunities. Perhaps most important, they fought for and to a large degree accomplished a revolution of traditional views of their role in society (Gender inequality, 2009).

Dramatic changes in working patterns have taken place in the UK, particularly in the rise of female in employment. Three quarters of households now have dual incomes, but female still take responsibility for most of the housework, according to research funded by the Economic and Social Research Council Despite institutional and legislative changes intended to reduce inequality and improve work-life balance, female are still finding themselves working long hours at home and at work and, for their trouble, generally receive less pay than their male equivalents. Of course, more affluent couples are able to afford to reduce their domestic burdens through hired help and by acquiring labor saving devices (innovations report, 2009). Income disparity between genders stems from processes that determine the quality of jobs and earnings associated with jobs. Earnings associated with jobs will cause income inequality to take form in the placement of individuals into particular jobs through individual qualifications or stereotypical norms. Placement of men or female into particular job categories can be supported through the human capital theories of qualifications of individuals or abilities associated with biological differences in men and female. Conversely, the placement of men or female into separate job categories is argued to be caused by social status groups who desire to keep their position through the placement of those in lower statuses to lower paying positions (innovations report, 2009)

The role of the female office worker is difficult to classify as either of the staff or line organization. In one sense, as it closely resembles the role of the factory worker or receptionist than any other role. In the days when industry was conducted on a relatively small scale, before the development of industrial bureaucracy, 
offices were corresponding small. Office employers were few in numbers, highly trained, relatively well educated as compared to shop workers, and in close personal contact with management. The private secretary was perhaps the most important worker in the old fashioned office. The private secretary, almost always a woman, was in close personal contact with the boss; she took his dictation, arranged his schedule for the day and performed a myriad of other tasks. (Schneider, 1957)

The enlargement, centralization and mechanization of the office have served to modify old office roles, to create new ones, and to relate these roles to each other in novel ways. One important development, which began as early as the 1920s is the increasing importance of the office manager. Before that time the management of the office was usually assigned as a part time duty to an official who held a position in line. After that time office managing became the work of a specialist who knew intimately the work of the office, who knew how to mange, how to route work. In other words, office management emerged as a fullfledged managerial position. At the same time, the old office role structure began to break down. This structure had been a hierarchy beginning with the relatively low paid typist and ascending through the stenographer who took dictation, to the private secretary who had numerous, often confidential duties. In the modern office the tendency has been to confine private secretaries to the very highest managerial position. Even the stenographer has departed. In the place of these specialists have come the dictating machines and a pool of typists to transcribe the recording. The office worker is today, largely judged in terms of universal criteria, particularly the norm of efficiency. The rather personal and relatively informal relationships of the pre bureaucratic office are largely things of the past. Office salaries today are lower than the wages of many skilled workers, and not much higher on the average than the wages of operatives. (Schneider, 1957)

Since the office role does not offer superior salary or escape from routinized work as regards, it would seem that its attractiveness lies in some nonmaterial reward such as "status". Office workers feel their roles to be strongly superior in this respect to those of normal shop workers. Office workers believe that their jobs demand high mental power, skill, and education, or at least apprenticeship. Furthermore, office workers seem to feel their claims to relatively high status are recognized by management in various ways; by permission to wear street clothing at work, by payment in salary rather than in wages, by somewhat different hours of work etc. There can be little doubt that the office workers drive for status has been highly useful to management. The office worker is typically from a middle class family which is anxious to attain or retain status. The office role becomes the symbol of the status wishes of this middle class element. Perhaps the most potent source of strain for the office worker has been the threat to what is most dear to her that is her status position. (Schneider, 1957)

The review of literature revealed that not a single study has been conducted on job satisfaction of female office clerks of government, multinational and local private business concerns in Bangladesh. In this study an attempt has been made to give a focus on job satisfaction of female office clerks of government, multinational and local private business concerns in Bangladesh. The study is undertaken with the following objectives:

a. To focus on the levels of job satisfaction of female office clerks in government, local private and multinational of Bangladesh.

b. To make a comparative study among government, multinational and local private business concerns of Bangladesh regarding job satisfaction.

\section{Review of Literature}

Most of the studies conducted on the job satisfaction of female office clerks have been reviewed in the subsequent section. Waters (1969) found from a sample of 160 female clerical workers that degree of overall satisfaction, overall dissatisfaction and overall satisfaction and dissatisfaction were correlated with several aspects of the work situation. The author also found that the results of these analyses offered no support for the two factor theory of job satisfaction. Williamson and Karras (1970) asked thirty four female clerical workers to rank 10 job characteristics in order of importance for self, importance for same sex and importance for opposite sex. These 10 job characteristics were taken from Herzberg, Maushe and Snyderman and 5 were hygiene and 5 were motivators. The results of these rankings were compared with the results obtained in two similar studies which used college females to rank the same 10 job characteristics. The results of this comparison showed a basic difference between the two different female groups. This difference is explained in terms of the college females' greater need for self-actualization and greater anticipation of opportunities for advancement, higher responsibilities, and the other motivators.

Grandjean and Taylor (1980) identified that the most influential reasons for the job dissatisfaction of clerical workers are declining prestige of clerical work and the unreliability of clerical workers for status 
claims. They also examined that training and the full use of one's skills are most strongly associated with satisfaction. Mansfield and others (1992) observed from 85 randomly selected female clerical workers that there were perceived social support from co-workers which are associated with job satisfaction. The authors also found that spouses or partners were effective buffers of adverse working conditions as well

Ting (1996) reported that job satisfaction is affected by major job and organizational factors as well as individual characteristics. He also explored by surveying the Federal employees that job satisfaction depends on pay satisfaction, promotion opportunity, task clarity and significance and skills utilization. Peretti-Watel, Constance, Seror and Beck (2009) explored the relationship between working conditions, job satisfaction and smoking behaviors among clerks and manual workers in the U.S. The data from French Health Barometer has been used by the researchers which was conducted a cross-sectional telephone survey among a national random sample. The study showed that poor working conditions have the potential to contribute health inequalities since they are likely to fuel stress and unhealthy behaviors which combine to increase in morbidity and mortality.

Sterns, Alexander, Barrett, and Dambrot (1983) explored from 175 Civil Service clerical employees that extraverts preferred jobs with higher levels of cognitive task demands, pace of task demands, cognitive closure, extrinsic rewards, and intrinsic rewards. Except extrinsic rewards these preferences had small negative relation with Neuroticism. The researchers also found that Introverts were more satisfied than extraverts with work itself, supervision, and co-workers which were measured by the Job Descriptive Index. Morris and Long (2002) examined relations among persons and social resources, work stress appraisal and depression with data from two longitudinal studies of female clerical workers. Results were consistent with predictions that primary appraisals (i.e., threats to self-esteem) contribute to change in depression beyond the effects of person and social resources and negative affectivity. There was modest evidence that control appraisals moderate the effects of optimism and work support. The above review of literature revealed that not a single study has been conducted on job satisfaction of female office clerks of government, multinational and local private business concerns in Bangladesh.

\section{Methodology}

This work is based on both secondary and primary sources. The secondary sources of data include books and research articles written on office clerks, female and job satisfaction. Most of the data required for the study were collected from primary source through structured questionnaire. The study was confined to Dhaka City. The Dhaka city has been selected because Dhaka is the main center of government, multinational and local private business concerns in Bangladesh. Time and cost were other important considerations for such a decision. Because of the lack of sampling frame, convenient method of sampling was used. Initially, 300 female office clerks were taken as sample and after screening finally 255 female office clerks were taken for this study. In framing questionnaires for this study, the researchers consulted most of the studies conducted on job satisfaction and different books of female studies and organizational behavior. In order to focus on perceptions of female office clerks regarding job satisfaction in government, multinational and local private business organizations an index of job satisfactions consisted of 15-items was prepared.

\section{Results and Discussion}

All the collected data were edited, coded and classified by the researchers before making the final analysis. Factor analysis and regression analysis were used for analyzing the data

\subsection{Reliability test}

Cronbach's Alpha of local private, government, and multinational organizations is $0.875,0.800$, and 0.803 respectively. So, the data has passed the reliability as these are more than 0.6 (see table 1).

Table-1: Reliability test

\begin{tabular}{lcl}
\hline Types of Organization & Sample Size & Cronbach's Alpha \\
\hline Local Private & 175 & 0.875 \\
Public & 70 & 0.800 \\
Multinational & 10 & 0.803 \\
\hline
\end{tabular}




\subsection{Relative Importance of attitudes towards Job Satisf action}

The attitude towards job satisfaction is inter-related with their nature of human being. In this context many likings and dislikings of the employees arise from the work place. So, some factors such as working condition, salary, security, colleague's behavior, volume of work etc are very much related to job satisfaction. For this we have chosen factor analysis so that we can find out which factors have more impact on the job satisfaction.

\subsection{Government Organizations}

10 independent variables have divided into four factors using factor analysis with varimax rotation towards job satisfaction of local private organizations which have been shown in table 2 .

Table-2: Total Variance Explained of Government Organizations

\begin{tabular}{llll}
\hline \multirow{2}{*}{ Component } & \multicolumn{3}{c}{ Initial Eigen values } \\
\cline { 2 - 4 } & Total & \% of Variance & Cumulative \% \\
\hline 1 & 2.901 & 29.010 & 29.010 \\
2 & 2.230 & 22.301 & 51.310 \\
3 & 1.130 & 11.299 & 62.609 \\
4 & 1.070 & 10.698 & 73.307 \\
5 & .739 & 7.389 & 80.696 \\
6 & .539 & 5.393 & 86.090 \\
7 & .518 & 5.179 & 91.268 \\
8 & .429 & 4.292 & 95.560 \\
9 & .268 & 2.678 & 98.238 \\
10 & .176 & 1.762 & 100.000 \\
\hline Survey: 2009, Extraction Method: Principal Component Analysis
\end{tabular}

Table-3: Rotated Component Matrix (a) of Government organizations

\begin{tabular}{|c|c|c|c|c|}
\hline \multirow{2}{*}{ Variables } & \multicolumn{4}{|c|}{ Component } \\
\hline & 1 & 2 & 3 & 4 \\
\hline $\begin{array}{l}\text { a) Salary is competitive than other } \\
\text { companies }\end{array}$ & .873 & -.145 & .154 & -.133 \\
\hline b) Salary is equitable than my colleagues & .813 & .121 & -.098 & .031 \\
\hline $\begin{array}{l}\text { c) Salary is equitable than employees of } \\
\text { other jobs }\end{array}$ & .840 & .016 & -.108 & .054 \\
\hline d) Job security & -.059 & .173 & .788 & -.003 \\
\hline e) Employ promotion decision & .248 & -.142 & .276 & .786 \\
\hline f) Boss expectation from me & -.202 & .278 & .308 & .571 \\
\hline g) Job makes the best use of my ability & -.003 & .083 & .759 & .319 \\
\hline h) Work load is not burdensome & .015 & .786 & .496 & .073 \\
\hline i) I don't face time pressure & .044 & .918 & .072 & .169 \\
\hline j) Feel free to tell my boss what $\mathrm{i}$ think & -.129 & .413 & -.136 & .701 \\
\hline
\end{tabular}

Survey: 2009, Extraction Method: Principal Component Analysis. Rotation Method: Varimax with Kaiser Normalization., Rotation converged in 7 iterations.

The four factors, the authors have identified, having more than one eigenvalue and contain more than $73 \%$ cumulative variance of the data, are considered as justified which have been shown in table 1 . Factor 1 contains 'salary is competitive than other companies' (0.873); 'salary is equitable than my 
colleagues' (0.813); and 'salary is equitable than employees of other jobs' (0.840) variables. This factor consists of more than $29 \%$ of the variance of the data with eigenvalue of 2.901 . That means this factor contains more information than other factors. Factor 2 consists of 'work load is not burdensome' (0.883) and 'I don't face time pressure' (0.737) which loaded high on this factor. 'Job security' (0.788) and 'job makes the best use of my ability' (0.759) loaded high on the factor 3 and finally 'employ promotion decision' (0.786), 'boss expectation from me' (0.571) and 'feel free to tell my boss what I think' (0.701) loaded high on factor 4 .

\subsection{Local Private Organizations}

Using factor analysis the authors have identified three factors of the female office clerks' job satisfaction for the local private organizations which have been shown in table 4.

Table-4: Total Variance Explained of Local Private Organizations

\begin{tabular}{llll}
\hline \multirow{2}{*}{ Component } & \multicolumn{3}{c}{ Initial Eigen values } \\
\cline { 2 - 4 } & Total & \% of Variance & Cumulative \% \\
\hline 1 & 3.543 & 39.370 & 39.370 \\
2 & 1.830 & 20.336 & 59.706 \\
3 & 1.000 & 11.115 & 70.821 \\
4 & .656 & 7.290 & 78.111 \\
5 & .626 & 6.959 & 85.070 \\
6 & .472 & 5.246 & 90.316 \\
7 & .376 & 4.175 & 94.491 \\
8 & .279 & 3.102 & 97.593 \\
9 & .217 & 2.407 & 100.000 \\
\hline \multicolumn{2}{c}{ Survey: 2009, Extraction Method: Principal Component Analysis }
\end{tabular}

Table-5: Rotated Component Matrix (a) of Local Private Organizations

\begin{tabular}{|c|c|c|c|}
\hline \multirow{2}{*}{ Variables } & \multicolumn{3}{|c|}{ Component } \\
\hline & 1 & 2 & 3 \\
\hline a) Salary is competitive than other companies & .878 & .083 & .126 \\
\hline b) Salary is equitable than my colleagues & .896 & .059 & .136 \\
\hline $\begin{array}{l}\text { c) Salary is equitable than employees of other } \\
\text { jobs }\end{array}$ & .838 & .047 & .197 \\
\hline d) Job security & .101 & .088 & .846 \\
\hline e) Employ promotion decision & .428 & .120 & .679 \\
\hline f) Job makes the best use of my ability & -.079 & .762 & .214 \\
\hline g) Work load is not burdensome & .028 & .883 & .113 \\
\hline h) I don't face time pressure & .305 & .737 & .126 \\
\hline i) Feel free to tell my boss what i think & .096 & .324 & .654 \\
\hline
\end{tabular}

Survey: 2009, Extraction Method: Principal Component Analysis. Rotation Method: Varimax with Kaiser Normalization, Rotation converged in 5 iterations.

From table 4, it is also justified because these factors explain more than $70 \%$ of the cumulative variance of the data and have more than one eigenvalue. The most important factor for the job satisfaction of local private organizations is factor 1 which loaded high and consists of 'salary is competitive than other companies' (0.878), 'salary is equitable than my colleagues' (0.896), 'salary is equitable than employees of other jobs' (0.838) variables. This factor contains more than $39 \%$ of the variance of the data with the highest eigenvalue (3.543) which indicates that this factor provides maximum insights than the other 
factors. Variables 'job makes the best use of my ability' (0.762), 'work load is not burdensome' (0.883), 'I don't face time pressure' (0.737) loaded high on factor 2 . $3^{\text {rd }}$ factor of job satisfaction for the local private organizations contains 'job security' (0.846), 'employ promotion decision' $(0.679)$ and 'feel free to tell my boss what i think' $(0.654)$ which loaded high. The factor loadings of these variables indicate that the extracted variables are important for the job satisfaction of local private organization.

\subsection{Multinational Organizations}

Factor analysis using varimax rotation was performed among 10 independent variables towards job satisfaction of female office clerks for the multinational organizations which have been shown in table 6 .

Table-6: Total Variance Explained of Multinational Organizations

\begin{tabular}{llll}
\hline \multirow{2}{*}{ Component } & \multicolumn{3}{c}{ Initial Eigen values } \\
\cline { 2 - 4 } & Total & \% of Variance & Cumulative \% \\
\hline 1 & 2.103 & 35.053 & 35.053 \\
2 & 1.678 & 27.959 & 63.011 \\
3 & 1.180 & 19.661 & 82.672 \\
4 & .629 & 10.480 & 93.151 \\
5 & .235 & 3.925 & 97.076 \\
6 & .175 & 2.924 & 100.000 \\
\hline \multicolumn{2}{l}{ Survey: 2009, Extraction Method: Principal Component Analysis }
\end{tabular}

Table-7: Rotated Component Matrixes (a) of Multinational Organizations

\begin{tabular}{llll}
\hline \multirow{2}{*}{ Variables } & \multicolumn{1}{c}{ Component } & \\
\cline { 2 - 4 } & \multicolumn{1}{l}{$\mathbf{1}$} & $\mathbf{2}$ & $\mathbf{3}$ \\
\hline $\begin{array}{l}\text { a) Salary is competitive than other } \\
\text { companies }\end{array}$ & .839 & -.167 & .129 \\
$\begin{array}{l}\text { b) Salary is equitable than employees of } \\
\text { other jobs }\end{array}$ & .774 & .225 & -.037 \\
c) Boss expectation from me & -.175 & .915 & .024 \\
d) Job makes the best use of my ability & .565 & .056 & .754 \\
e) Work load is not burdensome & -.095 & .002 & .954 \\
f) I don't face time pressure & .266 & .900 & .012
\end{tabular}

Survey: 2009, Extraction Method: Principal Component Analysis. Rotation Method: Varimax with Kaiser Normalization, Rotation converged in 4 iterations.

The analysis has extracted three factors from the variables shown in table 6. It is justified because more than these three factors contain $82 \%$ cumulative variance and their eigenvalue is more than one which has been shown in table 5. Variables 'salary is competitive than other companies' (0.839) and 'salary is equitable than employees of other jobs' (0.774) loaded high on factor 1 . This is the most important support factor towards job satisfaction of multinational organization that accounts for more than $35 \%$ of the variance of the data with the highest eigenvalue (2.103) which indicates that this factor contains more information than the other factors. Factor 2 contains 'boss expectation from me' (0.915) and 'don't face time pressure' $(0.900)$ variables which loaded high. Finally 'job makes the best use of my ability' $(0.754)$ and 'work load is not burdensome' (0.954) loaded high on factor

\subsection{Job Satisfaction of Female Office Clerks in Government, Local Private and Multinational Organizations}

The types of organizations have significant impact on the variables of job satisfaction. To conduct a comparative study among female office clerks of government, local private and multinational organizations in Bangladesh regarding job satisfaction, the study has analyzed R Square values, regression significance, B value, coefficients significance of the factors of three types of organizations. Regression analysis (table 8) 
has been done subsequently with the four factors of government organizations, three factors of local private organizations and three factors of multinational organizations as independent variables and overall job satisfaction as dependent variable (such as 'satisfactory working condition', 'satisfaction of female colleagues behavior', 'satisfaction of male colleagues behavior', 'satisfaction of supervisor behavior' and 'satisfaction with benefits of my organization'). The authors have taken the mean value of all dependent variables and mean value of all independent variables under the corresponding factors.

Table-8: Regression analysis of Government, Local Private and Multinational Organizations

\begin{tabular}{llll}
\hline & Government & Local Private & Multinational \\
\hline R Square & 0.699 & 0.456 & 0.627 \\
Regression Sig. & $0.000^{*}$ & $0.000^{*}$ & $0.097^{* * *}$ \\
$\mathrm{~F}$ & 37.699 & 47.753 & 3.356 \\
\hline Note: ${ }^{*}$ 1\% significance level and ${ }^{* * *} 10 \%$ significance level &
\end{tabular}

Note: ${ }^{*} 1 \%$ significance level and ${ }^{* * *} 10 \%$ significance level

Table-9: Beta value and Coefficient Significance of Government, Local Private and Multinational Organizations

\begin{tabular}{lllllllll}
\hline \multicolumn{2}{l}{ Government } & \multicolumn{3}{l}{ Local Private } & \multicolumn{3}{l}{ Multinational } \\
\hline Factors & $\mathbf{B}$ & $\begin{array}{l}\text { Coefficie } \\
\text { nts Sig. }\end{array}$ & Factors & $\mathbf{B}$ & $\begin{array}{l}\text { Coefficie } \\
\text { nts Sig. }\end{array}$ & Factors & B & $\begin{array}{l}\text { Coefficients } \\
\text { Sig. }\end{array}$ \\
\hline F1 & .063 & 0.360 & F1 & 0.190 & 0.000 & F1 & -0.081 & 0.770 \\
F2 & .198 & 0.000 & F2 & 0.351 & 0.000 & F2 & 0.286 & 0.094 \\
F3 & .398 & 0.000 & F3 & 0.223 & 0.000 & F3 & 0.541 & 0.064 \\
F4 & .226 & 0.001 & & & & & & \\
\hline
\end{tabular}

From table 8, it can be said that the four factors of the government organizations correlate well with the job satisfaction. From the R Square value of the government organizations it can be interpreted that $69.9 \%$ of job satisfaction can be explained by these four factors of the government organizations and the remaining $30.1 \%$ can be explained by other factors. This model is statistically significant at $1 \%$ significance level which has been shown in table 8 . From the table 9 , it can be said that regarding salary the satisfaction of the female office clerks' of government organizations is very less which has came under F1 and it is not statistically significant at 5\% significance level. Because, coefficient significance of F1 is 0.360 and B value of this factor is 0.063 which is very less contribution in this model. F2 which contains workload and time issues have contributed more than the salary issues of satisfaction to the government employees. Among four factors of the regression model F3 has contributed most in the regression analysis which contains ' job security' and 'job makes the best use of the ability' variables. Because B value of this factor is 0.398 . F4 contributes second highest influence on job satisfaction of government organizations. That means 'employ promotion decision'; 'boss expectation'; and 'feel free to tell the boss' contribute $22.6 \%$ to satisfaction regarding job of the government organizations.

The authors have identified the model of female office clerks' job satisfaction for local private organizations which are statistically significant at $1 \%$ significance level. From the table 9 , it can be said that $45.6 \%$ of the job satisfaction of local private organizations can be explained by these factors. F1 which carries salary issues is statistically very much significant and has contributed $19 \%$ to the job satisfaction of the regression model. F2 which contains 'job makes the best use of the ability', 'workload' and 'does not face time pressure' has contributed $35.1 \%$ which is more than the salary to the satisfaction. Here there is contradiction. So the authors will analyze this in future that why it has come. F3 of the regression model has contributed $22.3 \%$ of the satisfaction. F3 explains 'job security', 'employ promotion decision' and 'feel free to tell the boss' variables. They are satisfied with these variables because in the local private organizations which have been taken as sample for analysis, the female office clerks have less complicated relationship with the boss and the system is less bureaucratic so that the clerks can share their thinking with the boss. Generally the promotion decision depends on performance. So their performance was good and they have got promotion and they have become satisfied with this. Now a day, in private organizations job security has increased. For that they are satisfied with this.

The relative importance of job satisfaction factors of female office clerks for multinational organizations on overall job satisfaction support the regression analysis (from table 8). This model is statistically significant at $10 \%$ significance level. For multinational Organizations, $62.7 \%$ of overall job satisfaction (table 8) can be explained by the variables which have been divided into three factors. F2 and F3 are statistically significant at $10 \%$ significance level (Table 9). From B value it can be said that F3 contributes more than the F1 and F2 in the job satisfaction because it contains $54.1 \%$ of B value. Factor F3 contains 
variables 'job makes the best use of my ability' and 'work load is not burdensome' which is related to performance. Since the sample female office clerks' performances are good, the employer can use their best ability.

\section{Conclusions}

The study finds that the level of job satisfaction of Bangladeshi female office clerks is at the positive level. However, the job satisfaction of female office clerks is significantly dependent upon salary; job security; promotion decision; less workload; less time pressure; boss expectation; best use of their ability and feel free to tell their opinion. The remaining factors working condition; co-worker relation; supervisor's behavior and other benefits do not have significant statistical evidence to improve the job satisfaction of female office clerks. Among three types of organizations female office clerks of government business organizations are comparatively more satisfied $(\mathrm{R}$ square $=0.699)$ than those from local private (R square $=$ 0.456 ) and multinational organizations (R square $=0.627$ ) as they are very much satisfied with their job security, best use of their ability, promotion decision, boss expectation and good relation with the supervisor. But the female office clerks of government business organizations are not satisfied with the salary. After government organizations the female office clerks of multinational organizations are satisfied with the use of their ability and workload. But the female office clerks of multinational business organizations are not satisfied with job security, good promotion decision and co-worker relation. Salary, time pressure and boss expectation are found less important factors towards job satisfaction of multinational female office clerks resulting in comparatively lower level of job satisfaction. There is more satisfaction of female office clerks for local private organizations regarding workload, time pressure, and use of their ability. They are also satisfied with the salary, job security, promotion decision and yield higher efficiency in work. The authors on the basis of the findings of their study would like to recommend some measures. The government business organizations of Bangladesh should focus on the salary of female office clerks as they are not satisfied with the salary. Since respondents of multinational business organizations of Bangladesh are not satisfied with job security, good promotion decision and co-worker relation, the concerned management should consider those issues. The female office clerks of local private business concerns of Bangladesh are not satisfied with the salary. So the management of said organizations should focus on this. Findings of this research can help to carry out further research to find out relationship between job satisfaction of female office clerks and their performance in government, local private and multinational business concerns of Bangladesh. Based on this research, a comparative study may also be carried out between male and female office clerks of the said organizations. The study can be helpful for the employees and management of the said organizations to know about the job satisfaction of female office clerks. The students and academicians who are studying and teaching organizational behavior can get information regarding the job satisfaction of female office clerks' in government, local private and multinational business concerns of Bangladesh.

\section{References}

Gammon, B. (2005): Mothers on the run: Despite more hours at work, there's always more to do at home. Retrieved from http://www.innovations-report.com/html/reports/social_sciences/report-40777.html

Gender Inequality (2010): Wikipedia. Retrieved from http://en.wikipedia.org/wiki/Gender_inequality

Grandjean, B. D. and Taylor, P. A. (1980): Job Satisfaction among Female Clerical Workers. Work and Occupation: An International Sociological Journal, 7 (1): 33-53.

Mahtab, N. (2007): Women in Bangladesh: From Inequality to Empowerment. Dhaka: A H Development Publishing House.

Mansfield, T. Phyllis K. (1992): Social Support and Job Satisfaction of Female Clerical Workers, Journal of Employment Counseling, 29: 113-16.

Morris, J. E. and Long, B. C. (2002): Female Clerical Workers' Occupational Stress: The Role of Person and Social Resources, Negative Affectivity and Stress Appraisals, Journal of Counseling Psychology, 49(4): 395.

Peretti-Water, P., Constance, J., Seror, V., Beck, F. (2009): Working Conditions, Job Dissatisfaction and Smoking Behaviors among French Clerks and Manual Workers, Journal of Occupational \& Environmental Medicine, 51 (3): 343-350.

Scheider, E. V. (1957): Industrial Sociology, The Social Relations of Industry and the Community. Inc. New York: Mc Graw Hall Book Company.

Sterns, L., Alexander, R., Barrett, G. and Dambrot, F. (1983): The Relationship of Extraversion and Neuroticism with Job Preferences and Job Satisfaction for Clerical Employees, Journal of Occupational Psychology, 56 (2), 145-153. 
Ting, Y. (1996): Analysis of Job Satisfaction of the Federal White-Collar Work Force: Findings from the survey of Federal employees, American Review of Public Administration, 26 (4): 439-456.

Waters, L., K. (1969): Correlates of Job Satisfaction and Job Dissatisfaction among Female Clerical workers. Journal of Applied Psychology, 53 (5): 388-391

Williamson, T. R. and Karras, E. J. (1970): Job Satisfaction Variables among Female Clerical Workers, Journal of Applied Psychology, 54 (4): 343-346 